\title{
Anti-Proliferative, Pro-Apoptotic, Anti-Migrative and Tumor-Inhibitory Effects and Pleiotropic Mechanism of Theaflavin on BI6FIO Melanoma Cells
}

This article was published in the following Dove Press journal: OncoTargets and Therapy

\author{
Lei Zhang ${ }^{1, *}$ \\ Shijie Meng ${ }^{2, *}$ \\ Bo Yan ${ }^{2, *}$ \\ Jie Chen ${ }^{2}$ \\ Li Zhou (iD ${ }^{2}$ \\ Letian Shan ${ }^{2}$ \\ Ying Wang ${ }^{3}$
}

'School of Biological and Chemical Engineering, Zhejiang University of Science and Technology, Hangzhou, People's Republic of China; ${ }^{2}$ The First Affiliated Hospital, Zhejiang Chinese Medical University, Hangzhou, People's Republic of China; ${ }^{3}$ School of Basic Medicine, Zhejiang Chinese Medical University, Hangzhou, People's Republic of China

*These authors contributed equally to this work
Correspondence: Letian Shan The First Affiliated Hospital, Zhejiang Chinese Medical University, No. 548 Binwen Road, Binjiang District, Hangzhou, 310053, People's Republic of China Email letian.shan@zcmu.edu.cn

Ying Wang

School of Basic Medicine, Zhejiang Chinese Medical University, No. 548 Binwen Road, Binjiang District, Hangzhou, 3 10053, People's Republic of China Email ellawang@zcmu.edu.com
Purpose: Theaflavin (TF) is a primary pigment of tea, exhibiting anti-proliferative, proapoptotic and anti-metastatic activities on cancer cell lines. However, it is unknown whether $\mathrm{TF}$ is effective in treating melanoma cells.

Methods: To determine the effects of TF on melanoma cells, we conducted in vitro assays of cell viability, DAPI staining, wound healing, transwell, and flow cytometry as well as in vivo experiments on B16F10-bearing mouse model. Real-time PCR (qPCR) and Western blot (WB) were conducted to explore the molecular actions of TF.

Results: The cell viability assay showed that TF exerted inhibitory effect on B16F10 cells in a dose-dependent manner from 40 to $400 \mu \mathrm{g} / \mathrm{mL}$, with $\mathrm{IC}_{50}$ values ranging from $223.8 \pm 7.1$ to $103.7 \pm 7.0 \mu \mathrm{g} / \mathrm{mL}$. Moreover, TF induced early and late apoptosis and inhibited migration/ invasion of B16F10 cells in a dose-dependent manner, indicating its pro-apoptotic and antimigrative effects. In vivo, TF significantly inhibited B16F10 tumor size in mice model from 40 to $120 \mathrm{mg} / \mathrm{kg}$, which exerted higher effect than that of cisplatin. The molecular data showed that TF significantly up-regulated the mRNA expressions of pro-apoptotic genes (Bax, Casp3, Casp8, c-fos, c-Jun, and $c-M y c$ ), up-regulated the protein expressions of apoptosis-related p53 and JNK signaling molecules (ASK1, phosphorylated Chk1/2, cleaved caspase 3, phosphorylated JNK, c-JUN, cleaved PARP, and phosphorylated p53), and downregulated the protein expressions of proliferation-related MEK/ERK and PI3K/AKT signaling molecules (phosphorylated MEK1/2, phosphorylated ERK1/2, phosphorylated PI3K, and phosphorylated AKT) as well as the expressions of MMP2 and MMP9.

Conclusion: It can be concluded that TB exhibited anti-proliferative, pro-apoptotic, antimigrative, and tumor-inhibitory effects on melanoma cells through pleiotropic actions on the above pathways. This study provides new evidence of anti-melanoma efficacy and mechanism of TF, contributing to the development of TF-derived natural products for melanoma therapy.

Keywords: theaflavin, apoptosis, B16F10, melanoma, JNK, p53

\section{Introduction}

Melanoma is one of the most aggressive cancers that tends to metastasize rapidly and difficult to treat. ${ }^{1}$ Notably, chemotherapy has been widely used as a mainstay treatment for melanoma. ${ }^{2}$ However, the chemotherapeutics, such as cisplatin and doxorubicin, induce apoptosis in melanoma and normal tissues. ${ }^{3,4}$ Moreover, melanoma is prone to resist chemotherapy, resulting in unsatisfactory outcomes. ${ }^{5}$ Immunotherapy has largely become a subject of pivotal focus by researchers in the exploration of novel treatments for melanoma. Nevertheless, a few patients still 
ineffectively respond to immunotherapy such as immune checkpoint inhibitors (eg, ipilimumab or nivolumab). ${ }^{6}$ Regardless of the therapy used, the pro-apoptotic effect on tumor cells determines the anti-cancer effectiveness. Furthermore, the anti-metastatic effect should be taken into consideration as a treatment option for melanoma. Therefore, effective medications that exhibit both proapoptotic and anti-metastatic effects on melanoma cells are promising therapeutics for melanoma treatment.

Recently, natural products have become a promising candidate of anti-cancer therapeutics, the application of which have reached maturity and attracted increasing interest. Natural products harbor significant potential and low side effects. ${ }^{7}$ Being the main reservoir of natural products, traditional Chinese medicine (TCM) has been applied for thousands of years, exerting pro-apoptotic, anti-metastatic, anti-angiogenic effects on tumor cells by herbs. $^{8,9}$ For instance, tea (Camellia sinensis (L.) O. Kuntze) is one of the most popular beverages across the globe, and tea leaves have been characterized as TCM by the earliest national pharmacopeia "Xin Xiu Ben Cao" (Newly Revised Materia Medica) in Tang Dynasty of China (AD 659). Based on the TMC theory, tea leaves regulate pathogenic factors of chronic disease and cancers, including body temperature, phlegm, and toxins. Modern epidemiological surveys have reported that drinking more than 10 cups of tea per day significantly prevents the occurrence of cancer, confirming the anti-cancer potential of tea. ${ }^{10}$ Theaflavin (TF) is a primary pigment of tea produced by the oxidation of catechins in tea leaves during fermentation, and its concentration reaches approximately $30 \mathrm{mg} / \mathrm{mL}$ in the extract of tea leaves. ${ }^{11}$ It acts against various tumor cells by inducing cell apoptosis. ${ }^{12,13}$ The anti-cancer effects of TF have been reported on breast carcinoma, ovarian carcinoma, and hepatocellular carcinoma cells. Besides, a recent study reported that TF exhibits anti-metastatic activity on cancer cells, suggesting its potential role in treating tumors with a high risk of metastasis, such as melanoma. ${ }^{14}$

However, little attention has been paid to the activity of TF on melanoma to date. Considering the pro-apoptotic and anti-metastatic activities of $\mathrm{TF}$ on several tumor cells, ${ }^{14,15}$ we hypothesize that TF might be effective in treating melanoma. To validate this hypothesis, this study performed cellular experiments to evaluate the proapoptotic and anti-migrative effects of TF on melanoma cells (B16F10 cells) and conducted an animal experiment to determine its tumor-inhibitory effect. Further experiments were conducted to assess the molecular mechanism of TF.

\section{Materials and Methods}

\section{Chemicals and Reagents}

Theaflavin (TF, $>95 \%$ of purity) was purchased from Theabio Co., Ltd (Hangzhou, China) (Batch number: 20181211061). Dulbecco's modified Eagle's medium (DMEM) containing high glucose was purchased from HyClone Laboratories (UT, USA). Fetal bovine serum (FBS) was purchased from Cell Max (Beijing, China). Trypsin was purchased from Gibco (NY, USA). Cell Counting Kit 8 (CCK-8) was purchased from Bimake (Houston, USA). Annexin-V: FITC apoptosis detection kit was purchased from BD Biosciences (CA, USA). DAPI (4'-6-diamidino-2-phenylindole) staining solution was purchased from Thermo Fisher Scientific (MA, USA). Primary antibodies were obtained from Cell Signaling Technology (MA, USA). Trizol reagent and real-time polymerase chain reaction (real-time PCR) kit were obtained from TaKaRa (Dalian, China). Cisplatin $(5 \mathrm{mg} / \mathrm{mL}$ ) was purchased from Hansoh Pharma (Jiangsu, China).

\section{Cell Line and Animal Preparation}

The mouse B16F10 melanoma cell line was purchased from Shanghai Cell Bank of Chinese Academy of Sciences (Shanghai, China) and cultured in DMEM medium containing $10 \% \mathrm{FBS}$ at $37^{\circ} \mathrm{C}$ in a humidified $5 \% \mathrm{CO}_{2}$ incubator. The medium was daily changed, and the cells were treated with $\mathrm{TF}$ in their logarithmic growth phase. Male C57BL/6 mice weighing 20 to $22 \mathrm{~g}$ were purchased from Shanghai Laboratory Animal Center of Chinese Academy of Sciences (Grade SPF II, SCXK2012-0002) and housed under pathogen-free conditions with a 12 $\mathrm{h}$ light/dark cycle. Food and water were provided $a d$ libitum. All mice were treated in strict accordance with the China legislation on the use and care of laboratory animals. The animal experiment was approved by the Medical Norms and Ethics Committee of Zhejiang Chinese Medical University (approval number: ZSLL2018-049; date: 2018-01).

\section{Cell Viability Assay}

The inhibitory effect of TF on B16F10 cells was evaluated by cell viability assay using CCK- 8 . The $\mathrm{B} 16 \mathrm{~F} 10$ cells were seeded into 96 -well plates at $6 \times 10^{3}$ cells/well in 200 
$\mu \mathrm{L}$ medium for $24 \mathrm{~h}$ adherence, followed by treatment with TF at concentrations of $0,40,80,120,160,200,250,300$, $350,400 \mu \mathrm{g} / \mathrm{mL}$ for $24 \mathrm{~h}$ and $48 \mathrm{~h}$. Then, CCK-8 solution was added to each well and incubated at $37^{\circ} \mathrm{C}$ for $2 \mathrm{~h}$. The optical density value (OD value) was measured at $490 \mathrm{~nm}$ with Biorad microplate reader (CA, USA). Inhibitory rate $(\%)=[1-(\mathrm{TF}-$ treated OD/untreated OD) $] \times 100 \%$. The $50 \%$ inhibitory concentrations $\left(\mathrm{IC}_{50}\right)$ for $24 \mathrm{~h}$ and $48 \mathrm{~h}$ were calculated by regression analysis. Accordingly, the low, middle, and high concentrations of TF were determined for the following experiments.

\section{Clonogenic Assay}

Plate clonogenic assay was applied to test clone formation capability of B16F10 cells. Each 600 cells was added into each well of a 6-well plate and treated with TF at 0,100 , 200 , and $300 \mu \mathrm{g} / \mathrm{mL}$ for $24 \mathrm{~h}$, followed by medium-change and cultivation for 12 days to form cell clones. Afterwards, the cells were fixed in $4 \%$ formaldehyde for $30 \mathrm{~min}$, and then stained with crystal violet for $15 \mathrm{~min}$. More than 50 cell clones were counted for each group.

\section{DAPI Staining and Flow Cytometry Assay}

The pro-apoptotic effect of TF was evaluated by DAPI staining and flow cytometry assay using annexin-V/PI staining. For DAPI staining, B16F10 cells were seeded into 24-well plates at $1.5 \times 10^{5}$ cells/well and treated with $\mathrm{TF}$ at low, medium, high concentrations for $24 \mathrm{~h}$, followed by fixation with $4 \%$ paraformaldehyde in PBS for $30 \mathrm{~min}$ at room temperature and staining with DAPI for $10 \mathrm{~min}$ in dark. After wash for three times, the cells were observed using five coverslips under Carl Zeiss fluorescence microscope (Göttingen, Germany) and the apoptotic cells were counted. For flow cytometry assay, B16F10 cells were seeded into 6 -well plates at $3 \times 10^{5}$ cells/well for $24 \mathrm{~h}$ and treated with $\mathrm{TF}$ at low, medium, high concentrations for $72 \mathrm{~h}$. Afterwards, the cells were washed twice and labeled with annexin V-fluorescein isothiocyanate solution and PI in binding buffer. Fluorescence intensity of the cells was detected by BD C6 flow cytometry (CA, USA). The early apoptotic and late apoptotic cell rates (\%) were calculated.

\section{Cell Migration and Invasion Assay}

Wound healing assay and transwell assay were performed to test the anti-migrative and anti-invasive effect of TF. For wound healing assay, B16F10 cells at logarithmic phase were inoculated in 6 -well plates $\left(4 \times 10^{5} /\right.$ well $)$ and scratched by a pipette tip in cross form, followed by treatment of TF at 100, 200, and $300 \mu \mathrm{g} / \mathrm{mL}$. The DMEM medium contained only $1 \%$ FBS to minimize the proliferation component of cell migration. The cells were observed and imaged at 0,8 , and $16 \mathrm{~h}$ under an inverted microscope (CarlZeiss, Göttingen, Germany). Each experiment was conducted in triplicate, and the wound area (blank area) of each well was measured by Image J 1.47 software. As described previously, blank area ratio was calculated as the ratio of blank area of each well to average blank area of the well without TF treatment at $0 \mathrm{~h}$ (each blank area/average blank area with $0 \mu \mathrm{g} / \mathrm{mL} \mathrm{TF}$ at $0 \mathrm{~h}$ ) for statistical analysis. $^{16}$

Transwell assay was performed in 24-well transwell chambers with $8 \mu \mathrm{m}$ nitrocellulose pore filters (Corning Costar, NY, USA). Two hundred microliters of B16F10 cell $\left(2 \times 10^{5} / \mathrm{mL}\right)$ was loaded into the upper chamber, and $600 \mu \mathrm{L}$ serum-free medium with TF was added into the lower chamber. After incubation for $24 \mathrm{~h}$, the cells that passed through the chamber membrane were fixed with $4 \%$ paraformaldehyde (Servicebio, Wuhan, China) and stained with $1 \%$ crystal violet dye solution (Beyotime Biotechnology, Shanghai, China). As described previously, the migrated cell number was recorded by direct counting in five randomly selected regions of each well, and the average number was calculated for statistical analysis. ${ }^{16}$

\section{Real-Time PCR (qPCR) Assay}

The molecular action of TF at mRNA level was explored by qPCR assay using an ABI QuantStudio ${ }^{\mathrm{TM}} 7$ Flex Real-Time PCR System (Applied Biosystems, CA, USA). The total RNA of B16F10 cells was extracted using Trizol reagent and synthesized to cDNA via reverse transcription. The qPCR reaction system had a $20.0 \mu \mathrm{L}$ volume: $10 \mu \mathrm{L}$ SYBR $^{\circledR}$ Premix Ex Taq II (Tli RnaseH Plus), 0.8 $\mu \mathrm{L}$ PCR forward primer, $0.8 \mu \mathrm{L}$ PCR reverse primer, $2.0 \mu \mathrm{L}$ template cDNA, $0.4 \mu \mathrm{L}$ ROX reference dye, and $6.0 \mu \mathrm{L} \mathrm{ddH}_{2} \mathrm{O}$. The qPCR reaction condition was set to $95^{\circ} \mathrm{C}$ for $30 \mathrm{~s}$ initial denaturation, 40 cycles of $95^{\circ} \mathrm{C}$ for $5 \mathrm{~s}$ denaturation, $60^{\circ} \mathrm{C}$ for $34 \mathrm{~s}$ annealing, and $72^{\circ} \mathrm{C}$ for $40 \mathrm{~s}$ extension. At the end of each reaction, a melting curve analysis was performed. $\beta$ actin was used as reference gene and the $2^{-\Delta \Delta C T}$ method was applied to analyze the relative expression of each gene (Table 1).

\section{Western Blot (WB) Analysis}

The molecular action of TF at protein level was explored by WB analysis. Total proteins of B16F10 cells with TF treatment at $200 \mu \mathrm{g} / \mathrm{mL}$ were extracted using a lysis buffer 
Table I Primer Sequences Used for qPCR Analysis

\begin{tabular}{|l|l|l|}
\hline Gene & Forward Primer & Reverse Primer \\
\hline$\beta$-actin & 5'-CATCCGTAAAGACCTCTATGCCAAC-3' & 5'-ATGGAGCCACCGATCCACA-3' \\
\hline Bax & 5'-TGAAGACAGGGGCCTTTTTG-3' & 5'-AATTCGCCGGAGACACTCG-3' \\
\hline Casp3 & 5'-GGCCTGAAATACCAAGTCAGGAA-3' & 5'-CCATGGCTTAGAATCACACACACA-3' \\
\hline Casp8 & 5'-GAGATCCTGTGAATGGAACCTGGTA-3' & 5'-GTTCACGCCAGTCAGGATGCTA-3' \\
\hline Fos & 5'-CGGGTTTCAACGCCGACTA-3' & 5'-TGGCACTAGAGACGGACAGAT-3' \\
\hline c-Jun & 5'-TTCCTCCAGTCCGAGAGCG-3' & 5'-TGAGAAGGTCCGAGTTCTTGG-3' \\
\hline c-Myc & 5'-CTGTGGAGAAGAGGCAAACC-3' & 5'-TTGTGCTGGTGAGTGGAGAC-3' \\
\hline
\end{tabular}

(50 mM Tris- $\mathrm{HCl} \mathrm{pH}$ 7.4, $150 \mathrm{mM} \mathrm{NaCl}, 1 \mathrm{mM}$ EDTA, $1 \%$ Triton, $0.1 \%$ SDS, $5 \mu \mathrm{g} / \mathrm{mL}$ leupeptin, and $1 \mathrm{mM}$ PMSF) for $30 \mathrm{~min}$ on ice with repeated freezing and thawing. Targeted proteins were separated using denaturing sodium dodecyl sulfate polyacrylamide gel electrophoresis (SDS-PAGE) $(8 \sim 12 \%)$ and then transferred onto a PVDF membrane (Millipore, MA, USA). The membrane was blocked with $5 \%$ non-fat milk for $2 \mathrm{~h}$, followed by overnight incubation at $4^{\circ} \mathrm{C}$ with the antibodies against Actin, ASK1, phosphorylated Chk1 and Chk2 (p-Chk1 and p-Chk2), cleaved caspase 3 (c-CASP3), cleaved caspase 8 ( $c$-CASP8), JNK, phosphorylated JNK (p-JNK), and c-JUN, cleaved PARP (poly ADP-ribose polymerase), p53, phosphorylated p53 ( $p$-p53), MMP2, MMP9, phosphorylated ERK1/2 ( $p$-ERK1/2), phosphorylated MEK1/2 ( $p$-MEK1/2), phosphorylated AKT ( $p$-AKT), and phosphorylated PI3K ( $p$-PI3K). After incubation with secondary antibody, these proteins were visualized with an enhanced chemiluminescence kit (Amersham Pharmacia Biotech, Little Chalfont, UK) and detected using a chemiluminescence analyzer.

\section{Animal Experiment in Mice}

The tumor-inhibitory activity of TF was evaluated by animal experiment using B16F10-bearing mouse model. To establish the animal model, B16F10 cells $\left(1.0 \times 10^{5}\right.$ cells in $0.1 \mathrm{~mL}$ of PBS) were subcutaneously injected into 40 mice. The mice were randomly divided into four groups of 8 mice each: model group, TF-low dose (TF-L) group, TF-middle dose (TF-M) group, TF-high dose (TF-H) group, and cisplatin group as positive control. After the injection, mice in TF-L, TF-M, and TF-H groups were daily treated with $\mathrm{TF}$ at 40,80 , and $120 \mathrm{mg} / \mathrm{kg}$ by oral administration, respectively, for 21 days. Each mouse in the cisplatin group was daily treated with cisplatin at $0.0625 \mathrm{mg}$ by intraperitoneal injection for 21 days. Afterwards, all mice were sacrificed and the tumor size and weight were measured.

\section{Statistical Analysis}

Data were expressed as mean values $\pm \mathrm{SD}$ and subjected to one-way ANOVA, followed by Fisher's least significant difference (LSD) comparison. All analyses were performed using an updated version of DPS software. ${ }^{17}$

\section{Results}

\section{Anti-Proliferative Effect of TF}

Cell viability assay was performed to reflect the cell viability of melanoma cells and evaluate the effect of TF. As shown in Figure 1A, TF from 40 to $400 \mu \mathrm{g} / \mathrm{mL}$ significantly inhibited the viability of B16F10 cells and the inhibitory rate increased with the increasing concentrations of TF, indicating a dose-dependent manner. With the treatment of TF for $24 \mathrm{~h}$ and $48 \mathrm{~h}$, the $\mathrm{IC}_{50}$ were $223.8 \pm 7.1$ and $103.7 \pm 7.0 \mu \mathrm{g} / \mathrm{mL}$, respectively.

Clonogenic assay was performed to evaluate the antiproliferative effect of TF by testing clone formation capacity of B16F10 cells. As shown in Figure $1 F$ and $G$, the colony numbers of B16F10 cells were significantly decreased with TF treatment (100 to $300 \mu \mathrm{g} / \mathrm{mL}$ ), when compared with control numbers $(0 \mu \mathrm{g} / \mathrm{mL})$ (each $P<$ 0.01). The anti-clonogenic effect of TF was in a dosedependent manner.

\section{Pro-Apoptotic Effect of TF}

DAPI staining and flow cytometry were performed to evaluate the pro-apoptotic effect of TF on B16F10 cells. As shown in Figure 1B, apoptotic morphology, such as 

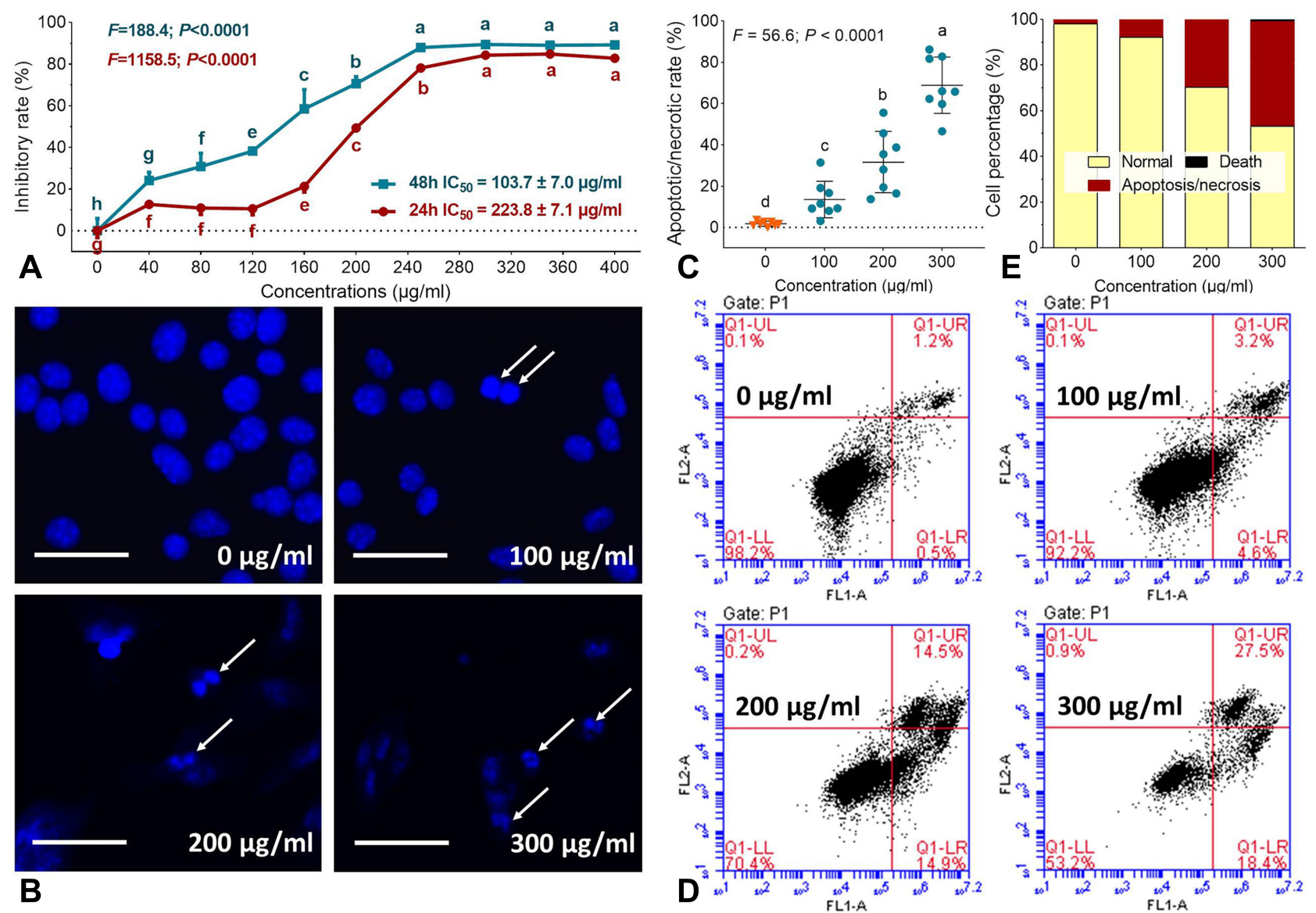

B
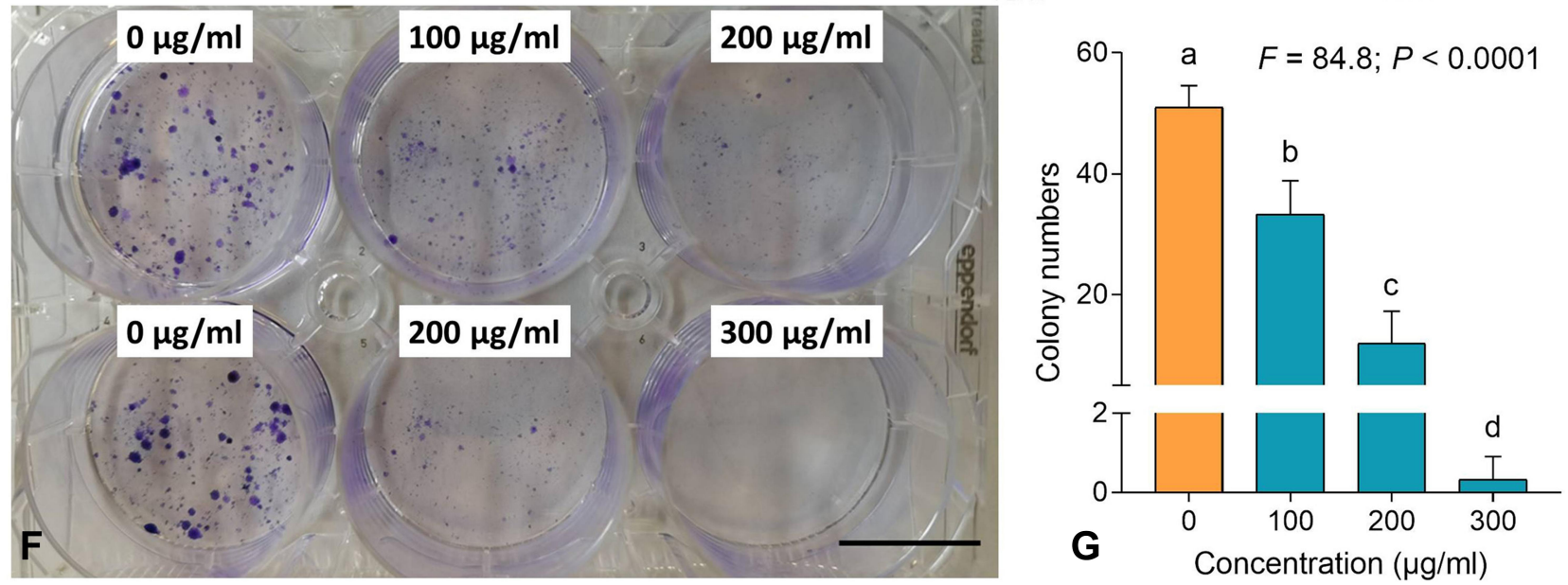

Figure I Cell viability (A), DAPI staining (B), apoptotic cell counting for DAPI staining (C), flow cytometry (D), cell percentages of apoptosis (E), clonogenic assay (F) and colony numbers $(\mathbf{G})$ of BI6FIO cells with treatments of TF. Data (mean \pm SD) points with different letters $(a, b, c, d, e, f, g$ and $h)$ indicate significant difference between each other [Fisher's least significant difference (LSD), $P<0.05$ ], and the values decrease with the order from a to $h$. Scale bar $=50 \mu \mathrm{m}$.

shrunken shape, karyopyknosis, and nuclear fragmentation, were seen with TF treatment from 100 to $300 \mu \mathrm{g} /$ $\mathrm{mL}$. Moreover, necrotic morphology was also observed as ruptures and high permeability of plasma membrane with TF treatment at 200 and $300 \mu \mathrm{g} / \mathrm{mL}$. The apoptotic/ necrotic cell rates were increased significantly with increasing concentrations of TF (each $P<0.01$ ), indicating a dose-dependent manner (Figure 1C). As shown in Figure 1D and E, the flow cytometry result showed that TF increased the percentages of apoptotic (upper right and lower right panels) B16F10 cells in a dose-dependent manner. The above results demonstrated that TF exerted dose-dependent pro-apoptotic effects on B16F10 cells. 


\section{Anti-Migrative and Anti-Invasive Effect of TF}

Wound healing assay was performed to test the antimigrative effect of $\mathrm{TF}$ on $\mathrm{B} 16 \mathrm{~F} 10$ cells. As shown in Figure $2 \mathrm{~A}, \mathrm{TF}$ at low to high dose range obviously blocked the healing of B16F10 cells following scratch wound within $16 \mathrm{~h}$. As shown in Figure 2B, the blank area ratios of the TF-treated cells were significantly higher than that of the untreated cells (each $P<0.01$ ) with increasing doses of TF, indicating a dose-dependent antimigrative effect on B16F10 cells. Although the concentration range of TF for wound healing assay was similar to that for cell viability assay and flow cytometry, the treatment time ( 8 and $16 \mathrm{~h}$ ) for wound healing assay was much shorter than that for other assays ( 24 and $48 \mathrm{~h}$ ). Thus, the cytotoxic effect of TF could be ignored, since TF at 8 and $16 \mathrm{~h}$ would not have much effect on the cytotoxicity. Transwell assay was performed to test the anti-invasive effect of TF on B16F10 cells. As shown in Figure 3, the number of B16F10 cells migrated to the bottom of chamber was significantly decreased with the elevated doses of TF when compared to NC (each $P<0.01$ ), indicating a dose-dependent inhibitory effect of $\mathrm{TF}$ on the cell invasion.

\section{Mechanism Underlying the Effects of TF}

qPCR assay was performed to clarify the modulatory action of TF on genes of B16F10 cells. As shown in Figure 4, TF significantly up-regulated the mRNA expressions of Bax, Casp3, Casp8, Fos, c-Jun, and c-Myc at a dose range from 100 to $300 \mu \mathrm{g} / \mathrm{mL}$, except for c-Jun with TF treatment at $100 \mu \mathrm{g} / \mathrm{mL}$. The up-regulatory effects were in a dose-dependent manner, except for that on $c-M y c$. Western blot was employed to analyze the expressions of apoptosis-, proliferation- and invasion-related proteins with the treatment of TF. As shown in Figure 5, the expressions of apoptosis-related proteins, including $p$-Chk1, $p$-Chk2, p-p53, c-CASP3 (19 kd and $17 \mathrm{kd}$ ), $c$-PRAP (89 kd), ASK-1, $p$-JNK (46 kd), and $c$-JUN were significantly up-regulated by $\mathrm{TF}$ at $200 \mu \mathrm{g} / \mathrm{mL}$ (each $\mathrm{P}<0.01$ ). The expressions of $\mathrm{p} 53$ and JNK were not significantly up-regulated, indicating their phosphorylations independent of protein overexpressions. As shown in Figure 6, the expressions of proliferation- and invasionrelated proteins, including $p$-MEK1/2, $p$-ERK1/2 (44 kd and $42 \mathrm{kd}$ ), $p$-PI3K ( $85 \mathrm{kd}$ and $55 \mathrm{kd}$ ), $p$-AKT, MMP2, and MMP9 (82 kd and $67 \mathrm{kd}$ ), were significantly down- regulated by $\mathrm{TF}$ from 100 to $300 \mu \mathrm{g} / \mathrm{mL}$ in a dosedependent manner (each $\mathrm{P}<0.01$ ), except for $p$-PI3K $(85 \mathrm{kd})$ with $\mathrm{TF}$ treatment at $100 \mu \mathrm{g} / \mathrm{mL}$.

\section{In vivo Tumor-Inhibitory Effect of TF}

Tumor sizes and weights were measured to evaluate the inhibitory effect of TF on melanoma in vivo. As shown in Figure 7, as compared with the model, TF obviously inhibited the tumor growth of $\mathrm{B} 16 \mathrm{~F} 10$ cells in mice at a dose range from 40 to $120 \mathrm{mg} / \mathrm{kg}$, with statistical decrease of tumor size with TF at 40 and $80 \mathrm{mg} / \mathrm{kg}$ and very significant decrease of tumor size with $\mathrm{TF}$ at $120 \mathrm{mg} / \mathrm{kg}(P<0.01)$. Also, the effect of TF-H was significantly higher than that of cisplatin $(P<0.01)$. Apparently, the B16F10 tumor weight was also decreased by TF at its dose range.

\section{Discussion}

This study conducted in vitro and in vivo experiments which demonstrated the apoptosis-inducing and tumorinhibitory effects of TF on melanoma B16F10 cells. The similar efficacy of TF on one human melanoma cell line (A875) was also determined (Figure S1 to S3). It was found that the in vivo effect of TF was even higher than that of cis-platinum at its safe dose. Moreover, we clarified that TF activated p53 and JNK signaling pathways with its apoptosis-inducing property and inhibited MEK/ERK and PI3K/AKT signaling pathways with its anti-proliferative property. This study contributed to the innovation discoveries of $\mathrm{TF}$ as follows: 1) determination of TF's antimelanoma efficacy on B16F10 cells; and 2) clarification of TF's pleiotropic mechanism of action mediated by p53, JNK, MEK/ERK and PI3K/AKT signaling pathways. Previous studies have reported that TF exerted inhibitory effects on human colon cancer cells, ovarian cancer cells, HeLa cells, liver cancer cells, mammary epithelial carcinoma cells, and esophageal squamous carcinoma cells, and the p53, JNK, PI3K/AKT, NF- $\kappa B$, and MAPK signaling pathways were found mediated TF's mechanisms. ${ }^{15,18-23}$ Nevertheless, MEK/ERK signaling-mediated anti-cancer mechanism of TF remained unclarified, which was firstly reported by our study.

As a result, these findings provided new evidence of the anti-melanoma efficacy and mechanism of TF and promoted the development of natural products for melanoma therapy. The B16F10 cells we applied is the most widely used cell type of melanoma with an elevated metastatic potential that acts as a well-established preclinical model for evaluating the anti-melanoma efficacy of 

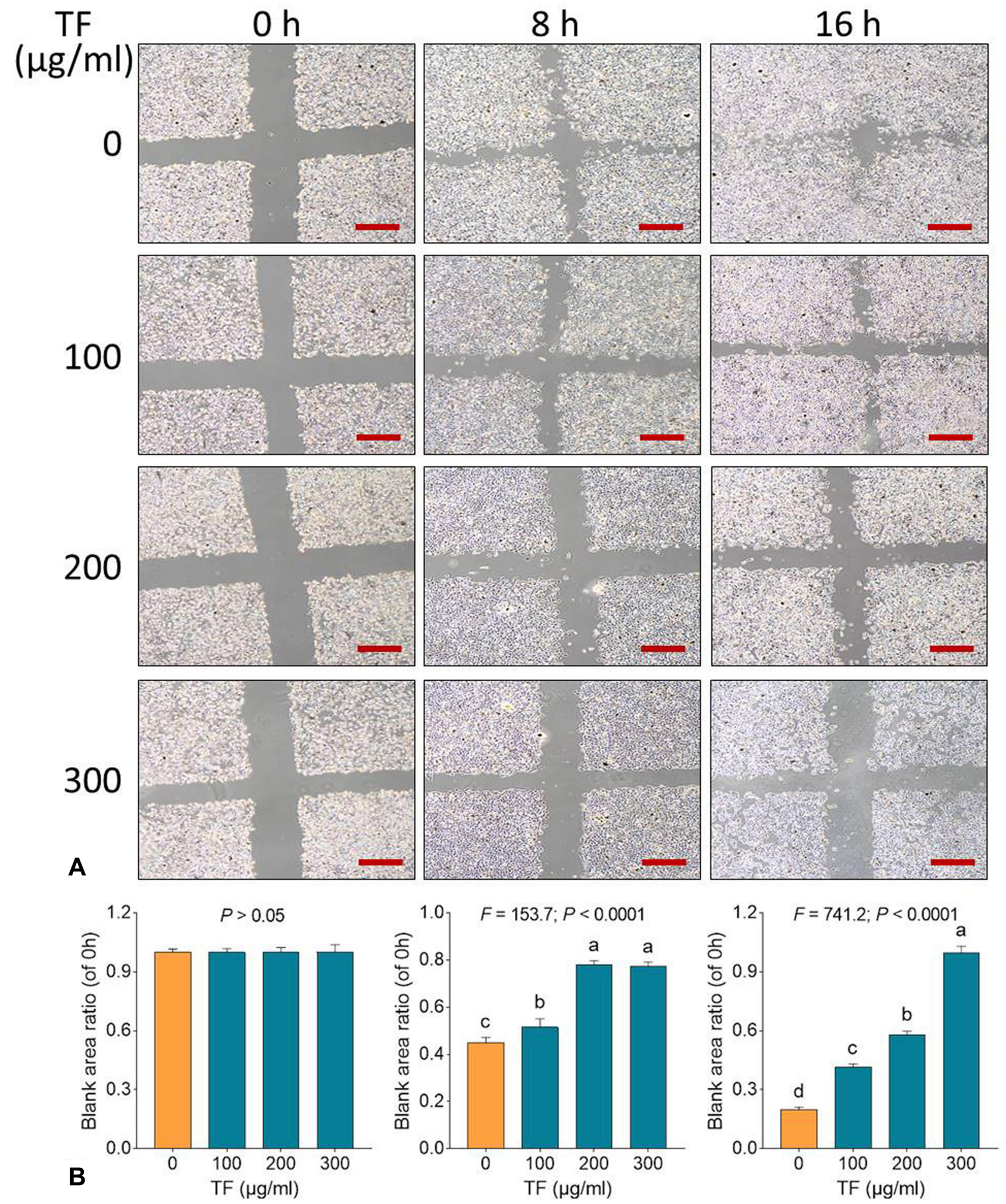

Figure 2 Wound healing assay (A) with statistical analysis of blank area ratios (B) on BI6FI0 cells with TF treatment. Data (mean \pm SD) points with different letters (a, b, c, and d) indicate significant difference between each other [Fisher's least significant difference (LSD), $P<0.05$ ], and the values decrease with the order from a to $\mathrm{d}$. Scale bar $=$ $500 \mu \mathrm{m}$. The experiment was repeated for three times. 

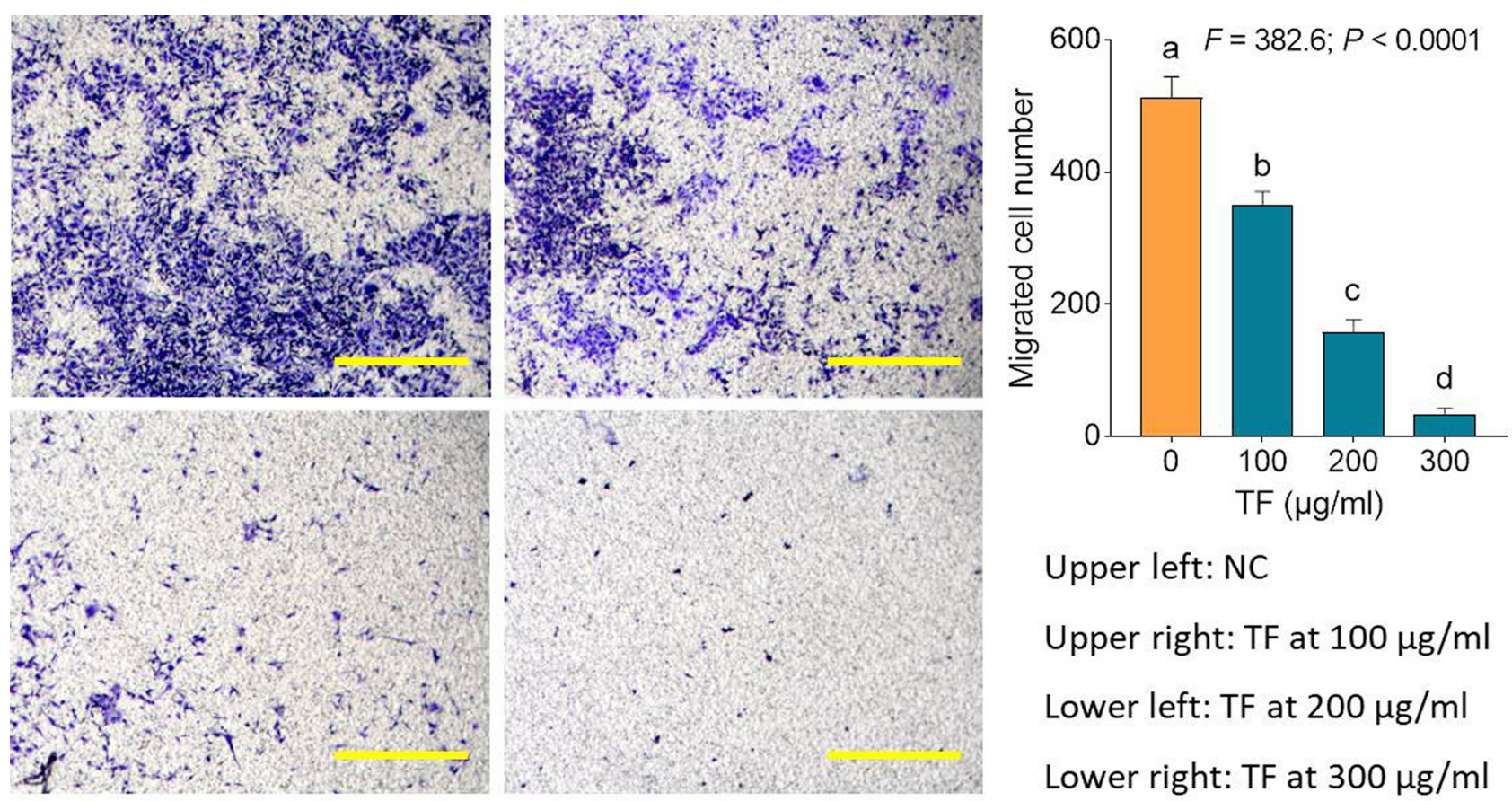

Upper left: NC

Upper right: TF at $100 \mu \mathrm{g} / \mathrm{ml}$

Lower left: TF at $200 \mu \mathrm{g} / \mathrm{ml}$

Lower right: TF at $300 \mu \mathrm{g} / \mathrm{ml}$

Figure 3 Transwell assay of BI6FI0 cells with TF treatments. Data (mean \pm SD) points with different letters (a, b, c, and d) indicate significant difference between each other [Fisher's least significant difference (LSD), $P<0.05$ ], and the values decrease with the order from a to d. Scale bar $=500 \mu \mathrm{m}$.

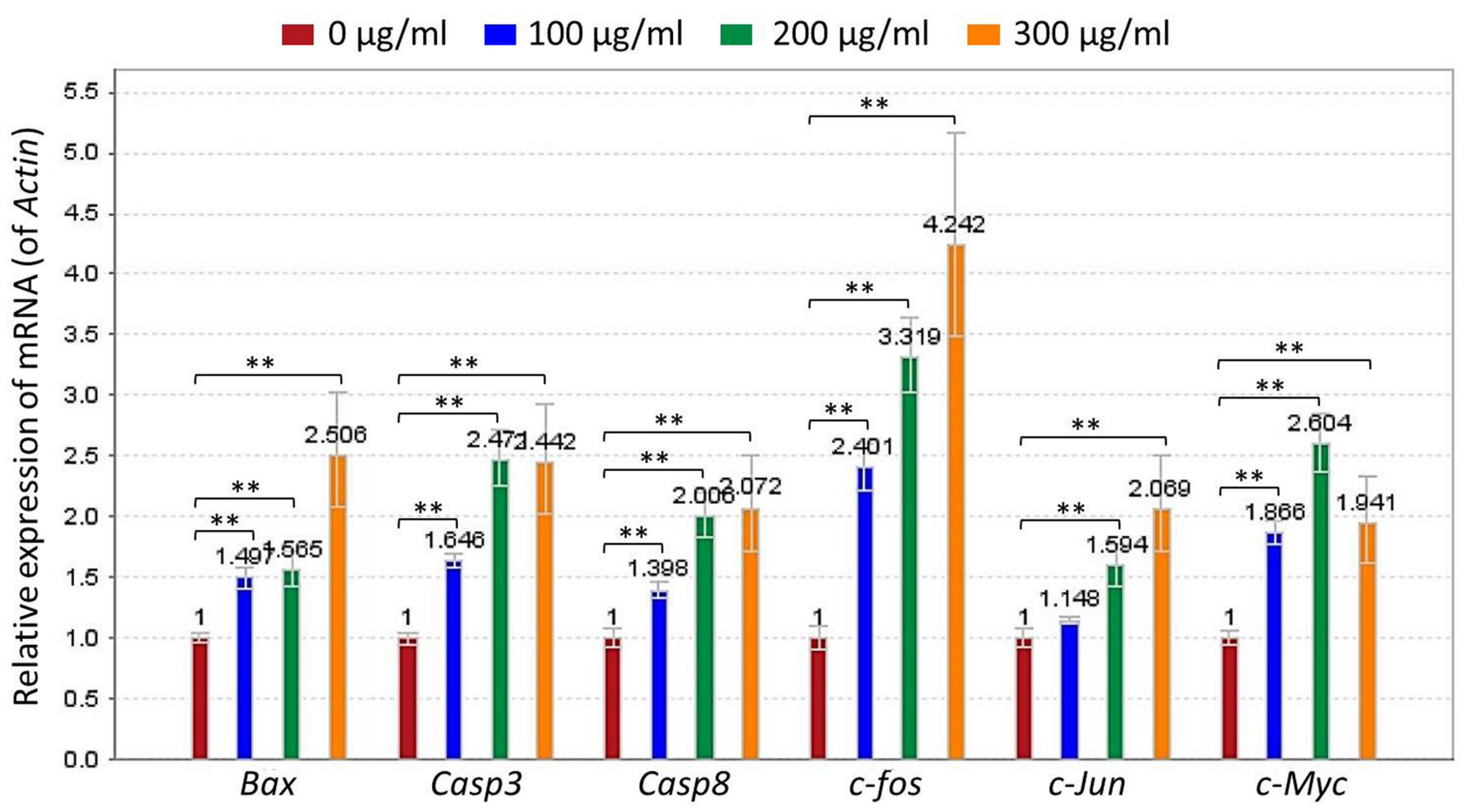

Figure 4 Relative mRNA expression of TF-targeted genes in BI6FI0 cells. Data were shown as mean \pm SD. $* * P<0.0 \mathrm{I}$ vs NC.

therapeutics. ${ }^{24}$ This model has important benefits over xeno-transplantation or genetically modified models since mice possess a normal immune system that opens a useful platform for new therapies and adequate host response. ${ }^{25}$ Moreover, B16F10 tumor growth drives proinflammatory response and muscle loss that are associated with impaired skeletal muscle strength and decreased locomotion and exploratory activity in 

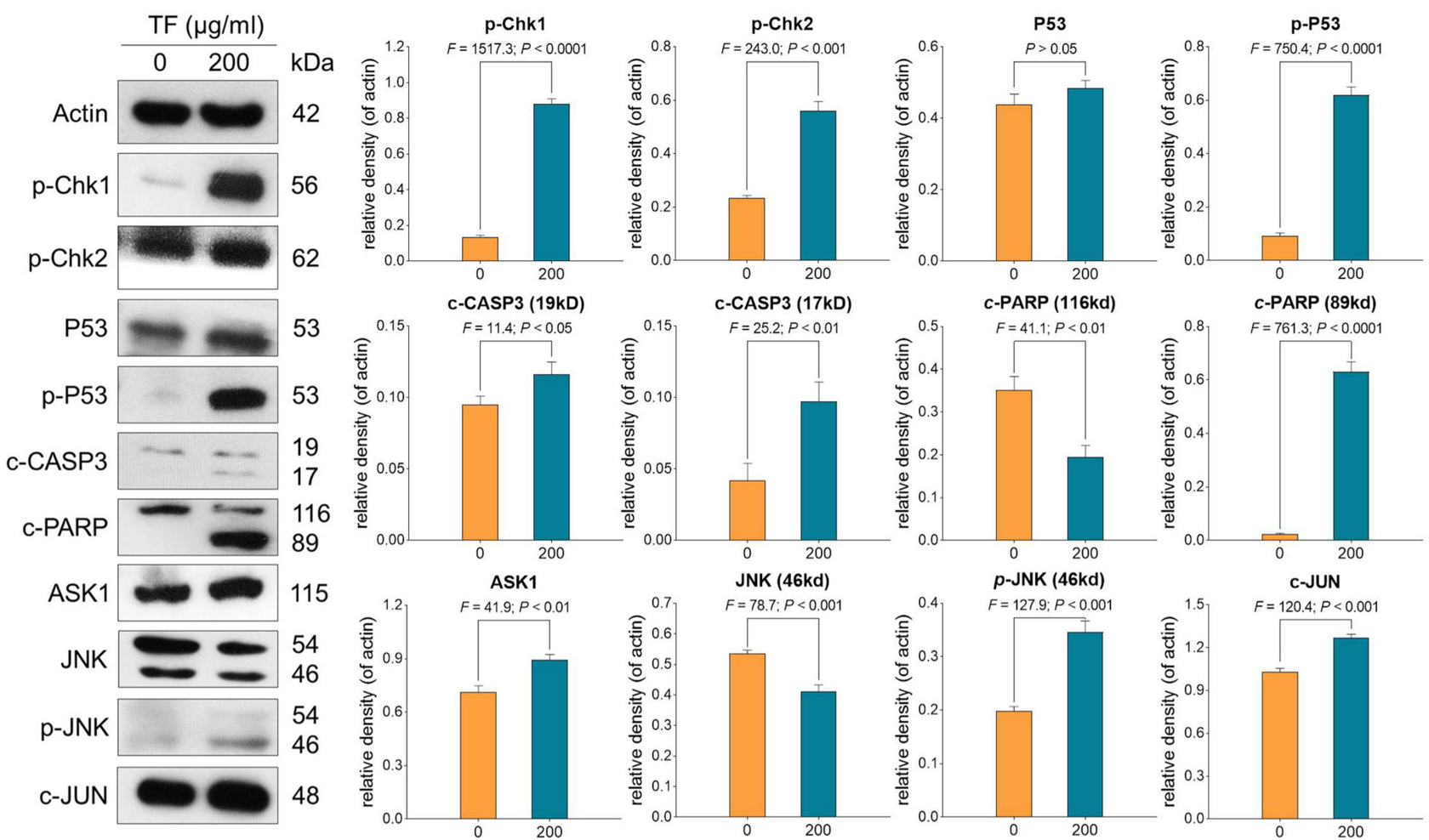

Figure 5 Expression and phosphorylation of apoptosis-related proteins in BI6FI0 cells with TF treatment. Data were shown as mean \pm SD.
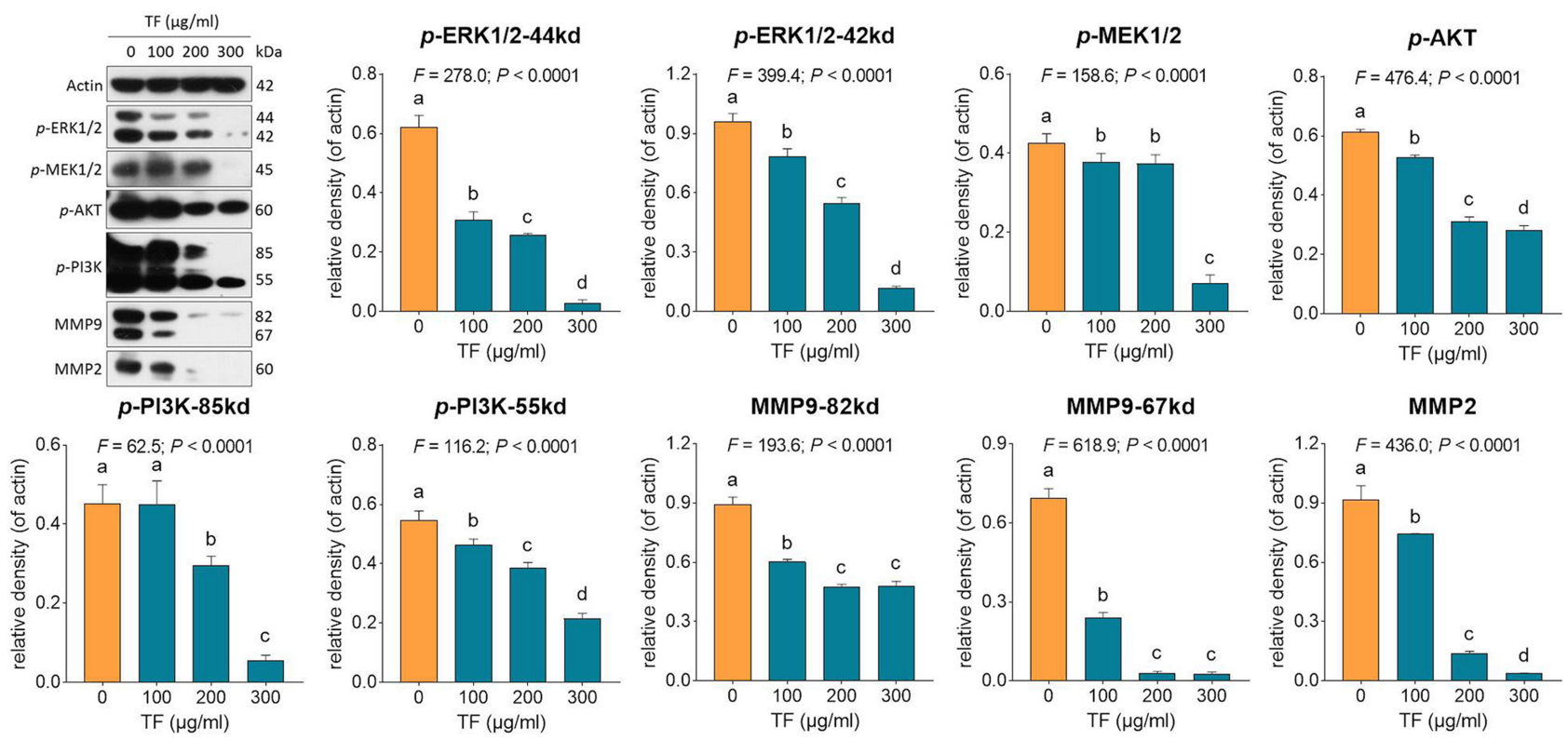

Figure 6 Expression and phosphorylation of proliferation- and invasion-related proteins in BI6FI0 cells with TF treatment. Data (mean \pm SD) points with different letters (a, b, c, and d) indicate significant difference between each other [Fisher's least significant difference (LSD), $P<0.05$ ], and the values decrease with the order from a to $d$.

B16F10 tumor-bearing mice, promoting cancer cachexia. $^{26}$ Therefore, this study implied that $\mathrm{TF}$ not only inhibited the melanoma growth and metastasis but also possessed additional effects on the tumor-driven catabolic state in response to inflammation, muscle loss, and even cachexia. Future studies are needed to explore such additional effects of TF against cachexia.

In this study, activated p53 signaling pathway was found to mediate the mechanism of pro-apoptotic and antimigrative effects of $\mathrm{TF}$ on melanoma cells. P53 was 

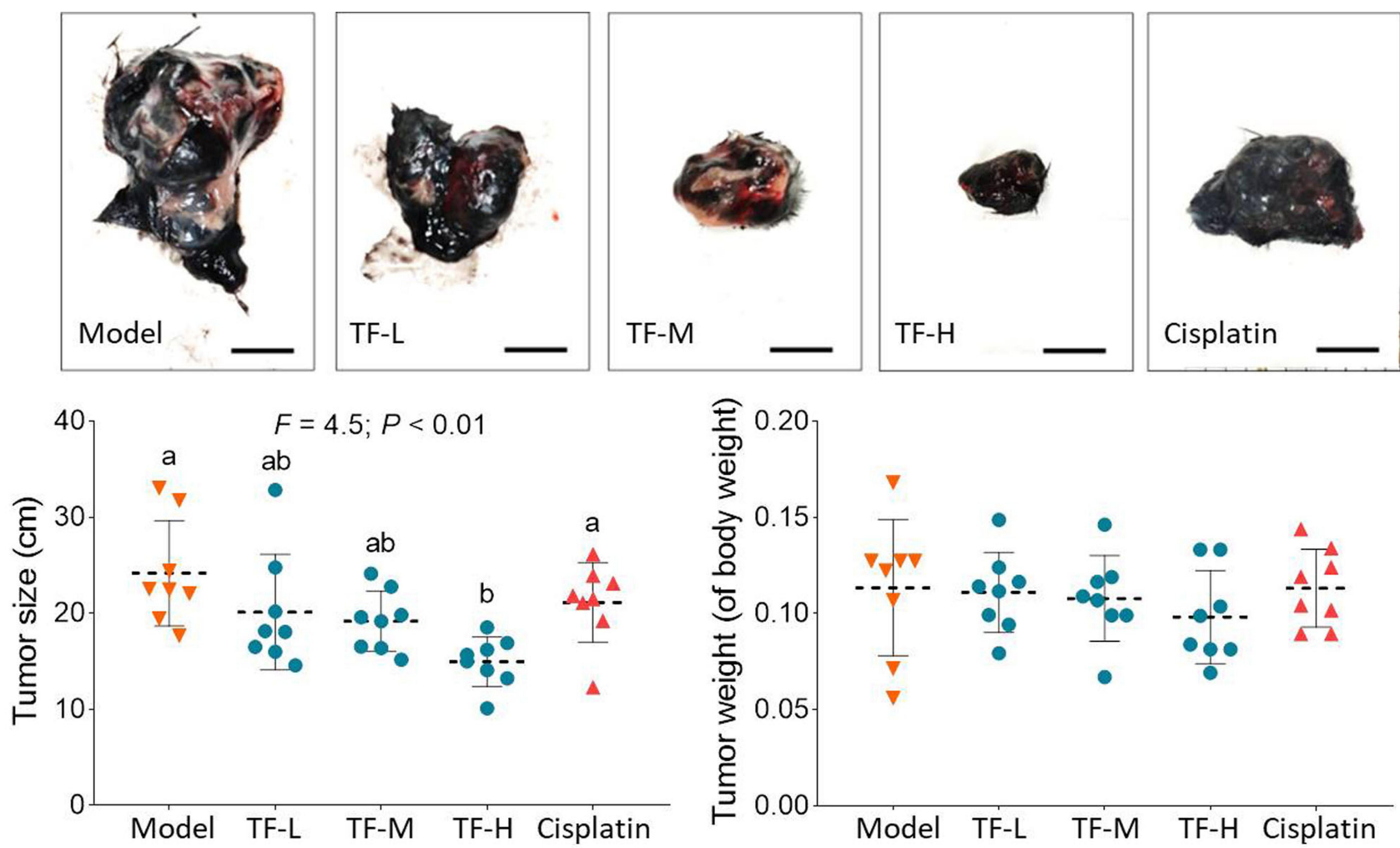

Figure 7 BI6FI0 tumor size and weight in mice with TF treatments $(n=8)$. Data (mean \pm SD) with different lowercase letters $(a$ and $b)$ indicate significant difference between each other [Fisher's least significant difference (LSD), $P<0.05$ ], and the values decrease with the order from a to b. Scale bar $=1 \mathrm{~cm}$.

considered as a tumor suppressor that regulates the expressions of several genes related to hundreds of biological functions associated with half of human cancers. ${ }^{27}$ By regulating genomic stability, p53 induces apoptosis of DNA-damaged cells and inhibits the migration of tumor cells. ${ }^{28}$ Additionally, p53 exhibits low mutation frequency (10 20\%) in melanoma, while it has high mutation frequency (50 70\%) in many other human cancers. ${ }^{29,30}$ Wild type p53 is prevalently expressed in $84 \%$ of human melanoma and its overexpression promotes suppression of melanoma development. ${ }^{31}$ By using genetically modified mice, previous studies have demonstrated that activation of p53 pathway is effective in the pro-apoptosis induction of melanoma cells. ${ }^{31,32}$ Here, the p53 pathway was activated by TF with phosphorylation of CHK1/2 and cleavage of CASP3, followed by the cleavage of PARP, which might mediate the apoptosis of B16F10 cells (Figure 8). Furthermore, phosphorylation of checkpoint kinases CHK1 and CHK2 promotes the phosphorylation of $\mathrm{p} 53$ and enhances the stability of $\mathrm{p} 53$, hence causing activation of CASP3. ${ }^{33}$ Notably, CASP 3 belongs to the caspase family member of 13 aspartate-specific cysteine proteases and promotes the formation of cleavage in cell apoptotic processes. ${ }^{34}$ Following the p53 signaling transduction, c-CASP3 cleaves PARP to induce cell apoptosis by producing nuclear DNA fragmentation. ${ }^{35}$ PARP is implicated in repairing single-strand DNA breaks and acts as a marker of cell apoptosis. ${ }^{36}$ Moreover, p53 degrades molecules involved in the migratory machinery for stabilizing junctions between cells, and hence the loss of p53 influences cell motility which further contributes to tumor metastatic potential. ${ }^{37,38}$ Along with the activated p53 signaling pathway, JNK signaling was also activated by TF in this study. JNK is another important pathway involved in apoptosis and metastasis of cancer cells. ${ }^{39,40}$ Activation of the JNK signaling pathway by chemotherapeutics (eg, doxycycline and docetaxel) triggers apoptosis response in melanoma cells. ${ }^{39,41,42}$ Also, by activating the JNK signaling pathway, natural products (eg, curcumin) exert an antimetastatic effect on melanoma cells. ${ }^{43}$ In this study, since TF up-regulated the expression of ASK1 as well as mediated phosphorylation of JNK and c-Jun, JNK pathway was activated along with the activation of $\mathrm{p} 53$ pathway in B16F10 cells (Figure 8). Notably, ASK1 belongs to the MAPKKK family and activates JNK signaling cascades. ${ }^{44}$ The up-regulation of ASK1 initiates the activation of the 


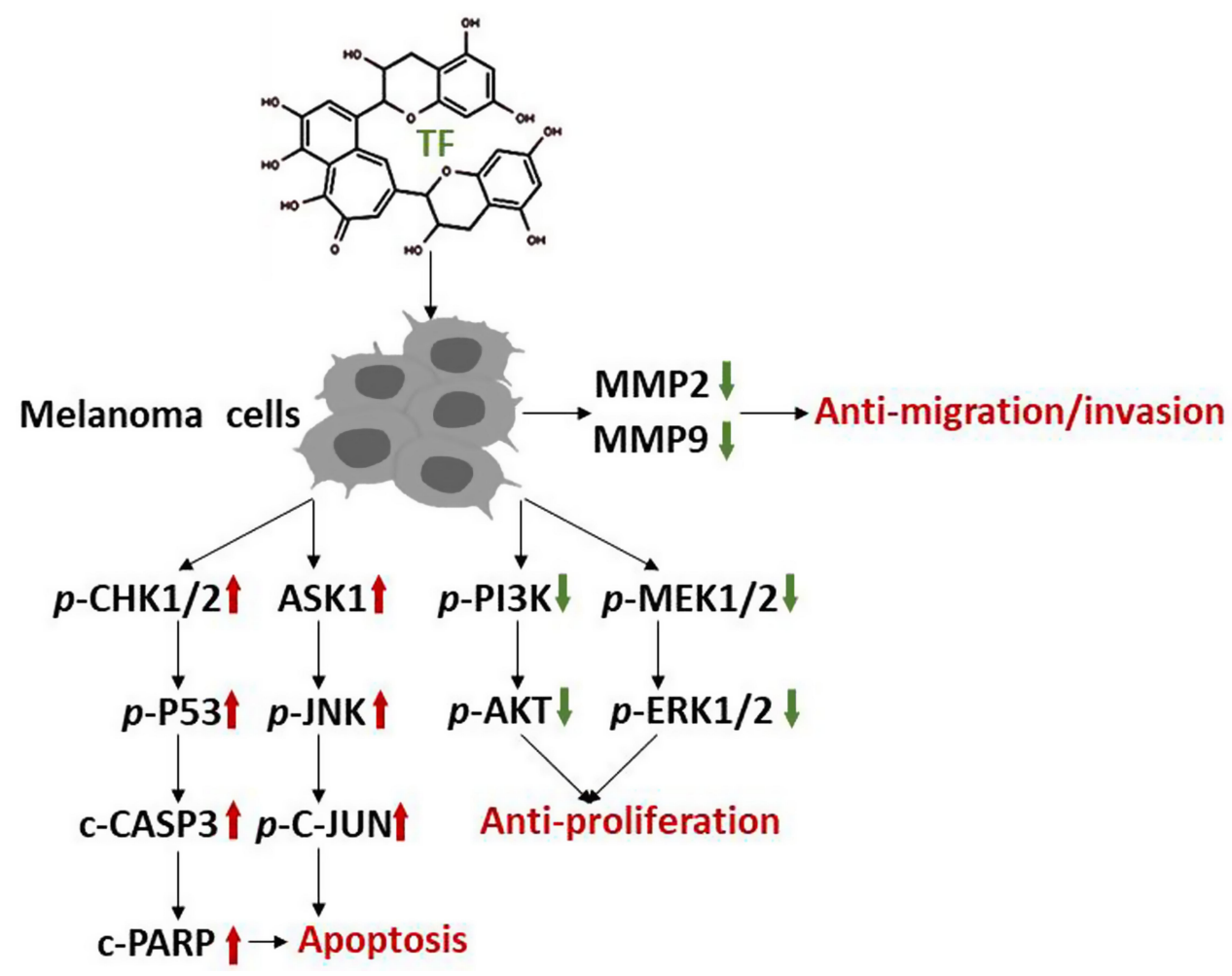

Figure 8 Overview of the anti-melanoma efficacy and mechanism of TF.

whole JNK signaling pathway which regulates cell survival and death balance in melanoma. ${ }^{40,45}$ Also, natural ingredients (eg quercetin) and chemotherapeutics (cisplatinum) have been confirmed to induce apoptosis of melanoma cells through the JNK pathway. ${ }^{46,47}$ Our findings indicate that since p53 is frequently mutated in cancer cell lines, the JNK pathway-mediated mechanism might be a by-pass anti-cancer mechanism of TF.

Contrarily, MEK/ERK and PI3K/AKT signaling pathways were found suppressed by TF, which participate in the cell proliferation and tumor growth of cancers. Of these, MEK/ERK is the key pathway for transduction of extracellular signals into cells, with participation in sorts of pathological processes (eg, proliferation, migration, and apoptosis) and close relation to occurrence, development and deterioration of tumors. ${ }^{48,49}$ The importance of aberrant activation of the MEK/ERK signaling pathway in tumorigenesis has been demonstrated in over $80 \%$ of cutaneous melanomas. ${ }^{50}$ As the major mediators of oncogene-induced melanoma formation, MEKs play a role in promoting cellular transformation and inhibiting apoptosis through transcriptional/post-transcriptional mechanisms. ${ }^{50}$ Upon activation, MEKs act as dual specificity kinases and phosphorylate the regulatory Tyr and Thr residues of ERKs, thereby causing the activation of ERK signaling cascade. ${ }^{51}$ Activated ERKs, the only known substrate for MEK phosphorylation, have been found in $90 \%$ of human melanomas. ${ }^{52}$ ERKs phosphorylate and activate a series of nuclear and cytoplasmic substrates that mediate the pleiotropic effects of this pathway, including regulation of proliferation and oncogenic transformation. ${ }^{51}$ PI3K/AKT signaling pathway is another important signaling pathway that plays a significant role in cancers, frequently in the setting of concurrent activation of MEK/ERK signaling. ${ }^{53}$ There is growing evidence that this pathway is frequently activated in melanomas and contributes to both melanoma initiation and therapeutic resistance. ${ }^{53}$ Activated PI3K recruits and activates AKT in most melanoma cell lines and melanoma samples of different progression stages. ${ }^{54}$ It has been demonstrated that increased $p$-Akt expression is significantly associated with melanoma progression and a worse patient survival. ${ }^{55}$ Moreover, AKT contributes to the invasiveness of melanoma cells by inhibiting anoikis and stimulating matrix metalloproteinase secretion. ${ }^{56}$ Inhibition of in vitro proliferation and in vivo tumor growth of human tumor cells has been described following blockade of the PI3K/AKT signaling pathway. ${ }^{57}$ There are also data that concurrent inhibition of MEK/ERK and PI3K/AKT signaling may be an effective 
Table 2 Selected Anti-Cancer Phytochemicals

\begin{tabular}{|c|c|c|c|c|c|}
\hline \multirow[t]{2}{*}{ Phytochemicals } & \multicolumn{4}{|c|}{ Signaling Pathways } & \multirow[t]{2}{*}{ Targeted Cancers } \\
\hline & P53 & JNK & PI3K & ERK & \\
\hline Berberine & $*$ & $*$ & & & Breast, colorectal, and prostate cancer. \\
\hline Catechins & & $*$ & * & & Breast, lung, prostate, and skin cancer, etc. \\
\hline Lycopene & & & * & $*$ & Prostate and colon cancer. \\
\hline Fisetin & $*$ & & $*$ & & Breast, colorectal, lung, prostate, and skin cancer, etc. \\
\hline Resveratrol & $*$ & & & $*$ & Breast, colorectal, lung, prostate, and skin cancer, etc. \\
\hline Curcumin & $*$ & & & $*$ & Breast, colon, lung, prostate, and skin cancer, etc. \\
\hline Celastrol & & $*$ & $*$ & & Breast, colon, lung, prostate, and skin cancer, etc. \\
\hline Chrysin & & & $*$ & $*$ & Colorectal cancer. \\
\hline Ursolic acid & $*$ & & $*$ & $*$ & Colon, lung, and liver cancer, etc. \\
\hline
\end{tabular}

therapeutic strategy for tumors. ${ }^{58,59}$ In this study, the expressions of $p$-MEK1/2, $p$-ERK1/2, $p$-PI3K, and $p$-AKT were decreased significantly by TF with a dose-dependent manner, indicating possible synergistic mechanism of $\mathrm{MEK}$ / ERK and PI3K/AKT signaling pathways in the antiproliferative effect of TF on melanoma cells.

Aside from TF, many other phytochemicals/bioactive compounds present in medicinal plants possess chemopreventive and chemotherapeutic effects against cancers, with lower toxicity on normal cells. Some of them suppress cancer cells by activating similar signaling pathways as that of TF, indicating similar manner of pleiotropic actions as TF. For instance, as shown in Table 2, berberine, catechins, lycopene, fisetin, resveratrol, curcumin, celastrol, chrysin, and ursolic acid have been found to exert effects against many cancers through pleiotropic actions on p53, JNK, PI3K, and ERK pathways. ${ }^{60,61}$ Most of these phytochemicals targeted on the similar cancer types, such as breast cancer, colorectal cancer, lung cancer, prostate cancer, and skin cancer (Table 2), suggesting that TF might possess similar effects on these cancers. Moreover, studies have reported that fucoxanthin, capsaicin, genistein, quercetin, piperine, eugenol, ursolic acid, luteolin, apigenin, curcumin, EGCG, and resveratrol exerted anti-cancer effects against melanoma through inhibition of angiogenesis, cell proliferation, metastasis, and cell cycle progression, and induction of cell apoptosis. ${ }^{62}$ The main mechanisms of action of these phytochemicals were related to the transcriptional modulation of $\mathrm{NF}-\kappa \mathrm{B}$, Notch-1, EGFR, ERK/MAPK, STAT, $\beta$-catenin, and $\mathrm{PI} 3 \mathrm{~K} / \mathrm{mTOR}$ pathways as well as the epigenetic modulation of DNA methylation, histone deacetylation, and miRNAs. ${ }^{63}$ Since phytochemicals have a synergistic effect in the treatment of cancers, ${ }^{64}$ further studies are warranted to explore the synergistic effect of TF with these phytochemicals in the treatment of melanoma.

\section{Conclusion}

For the first time, we demonstrated TF's anti-melanoma effects by using mice B16F10 cell line and clarified its mechanism mediated by the activations of p53 and JNK signaling and the suppression of MEK/ERK and PI3K/ AKT signaling. The anti-proliferative, pro-apoptotic, and anti-metastatic effects of TF were determined by in vitro assays, and the tumor-inhibitory effect was determined by in vivo experiment, the latter of which was even higher than that of cisplatin. Therefore, this study provides new evidence of the anti-melanoma efficacy of TF, contributing to the development of TF-derived natural products for melanoma therapy. Whether TF possesses in vivo anti-metastatic effect on melanoma or not, warranting further investigation.

\section{Acknowledgments}

This work was supported by National Natural Science Foundation of China (Grant No. 81774331 and 81873049), the Medical Health Science and Technology Project of Zhejiang Provincial Health Commission (grant no. 2012ZA045), and Zhejiang Provincial Key Construction University Superiority Characteristic Discipline (Traditional Chinese Pharmacology) Opening Foundation of China (Grant No. ZYX2018006).

\section{Disclosure}

The authors report no conflicts of interest in this work.

\section{References}

1. Siegel RL, Miller KD, Jemal A. Cancer statistics, 2018. CA Cancer J Clin. 2018;68(1):7-30. doi:10.3322/caac.21442 
2. Bhatia S, Tykodi SS, Thompson JA. Treatment of metastatic melanoma: an overview. Oncology. 2009;23(6):488-496.

3. CiRen B, Wang X, Long Z. The evaluation of immunotherapy and chemotherapy treatment on melanoma: a network meta-analysis. Oncotarget. 2016;7(49):81493-81511. doi:10.18632/oncotarget.13 277

4. Zhang QY, Wang FX, Jia KK, Kong LD. Natural Product Interventions for Chemotherapy and Radiotherapy-Induced Side Effects. Front Pharmacol. 2018;9:1253. doi:10.3389/fphar.2018.01 253

5. Leonardi GC, Falzone L, Salemi R, et al. Cutaneous melanoma: from pathogenesis to therapy (Review). Int $J$ Oncol. 2018;52(4):10 71-1080. doi:10.3892/ijo.2018.4287

6. Simon A, Kourie HR, Kerger J. Is there still a role for cytotoxic chemotherapy after targeted therapy and immunotherapy in metastatic melanoma? A case report and literature review. Chin $J$ Cancer. 2017;36:10. doi:10.1186/s40880-017-0179-6

7. Dutta S, Mahalanobish S, Saha S. Ghosh S and Sil PC. Natural products: an upcoming therapeutic approach to cancer. Food Chem Toxicol. 2019;128:240-255.

8. Hosseini A, Ghorbani A. Cancer therapy with phytochemicals: evidence from clinical studies. Avicenna J Phytomed. 2015;5:84-97.

9. Choi EO, Lee H, HwangBo H, et al. Citrus unshiu peel suppress the metastatic potential of murine melanoma $\mathrm{B} 16 \mathrm{~F} 10$ cells in vitro and in vivo. Phytother Res. 2019;33:3228-3241. doi:10.1002/ptr.6497

10. Imai K, Suga K, Nakachi K. Suga $K$ and Nakachi K. Cancer-preventive effects of drinking green tea among a Japanese population. Prev Med. 1997;26(6):769-775. doi:10.1006/pmed.19 97.0242

11. Vijaya K, Ananthan S, Nalini R. Antibacterial effect of theaflavin, polyphenon 60 (Camellia sinensis) and Euphorbia hirta on Shigella spp.-a cell culture study. $J$ Ethnopharmacol. 1995;49:115-118. doi:10.1016/0378-8741(95)90039-X

12. Li B, Vik SB, Tu Y. Vik SB and Tu Y. Theaflavins inhibit the ATP synthase and the respiratory chain without increasing superoxide production. J Nutr Biochem. 2012;23(8):953-960. doi:10.1016/j. jnutbio.2011.05.001

13. Pan H, Wang F, Rankin GO, Rojanasakul Y, Tu Y, Chen YC. Tu $\mathrm{Y}$ and Chen YC. Inhibitory effect of black tea pigments, theaflavin-3/ 3 '-gallate against cisplatin-resistant ovarian cancer cells by inducing apoptosis and G1 cell cycle arrest. Int $J$ Oncol. 2017;51(5):15 08-1520. doi:10.3892/ijo.2017.4145

14. Shao J, Meng Q, Li Y. Meng Q and Li Y. Theaflavins suppress tumor growth and metastasis via the blockage of the STAT3 pathway in hepatocellular carcinoma. Onco Targets Ther. 2016;9:4265-4275. doi:10.2147/OTT.S102858

15. Lahiry L, Saha B, Chakraborty J, et al. Contribution of p53-mediated Bax transactivation in theaflavin-induced mammary epithelial carcinoma cell apoptosis. Apoptosis. 2008;13(6):771-781. doi:10.1007/ s10495-008-0213-x

16. Yan L, Zhou L, Yan B, et al. Growth factors-based beneficial effects of platelet lysate on umbilical cord-derived stem cells and their synergistic use in osteoarthritis treatment. Cell Death Dis. 2020;11 (10):857. doi:10.1038/s41419-020-03045-0

17. Tang QY, Zhang CX. Data Processing System (DPS) software with experimental design, statistical analysis and data mining developed for use in entomological research. Insect Sci. 2013;20:254-260. doi:10.1111/j.1744-7917.2012.01519.x

18. Sang S, Lambert JD, Tian S, et al. Enzymatic synthesis of tea theaflavin derivatives and their anti-inflammatory and cytotoxic activities. Bioorg Med Chem. 2004;12(2):459-467. doi:10.1016/j. bmc.2003.10.024

19. Tu YY, Tang AB, Watanabe N. The theaflavin monomers inhibit the cancer cells growth in vitro. Acta Biochim Biophys Sin. 2004;36 (7):508-512. doi:10.1093/abbs/36.7.508
20. Song YA, Park YL, Yoon SH, et al. Black tea polyphenol theaflavin suppresses LPS-induced ICAM-1 and VCAM-1 expression via blockage of NF- $\mathrm{kB}$ and JNK activation in intestinal epithelial cells. Inflamm Res. 2011;60(5):493-500. doi:10.1007/s00011-010-0296-z

21. Gao Y, Rankin GO, Tu Y, Chen YC. Inhibitory Effects of the Four Main Theaflavin Derivatives Found in Black Tea on Ovarian Cancer Cells. Anticancer Res. 2016;36(2):643-651.

22. Chakrabarty S, Nag D, Ganguli A, Das A, Ghosh Dastidar D, Chakrabarti G. Theaflavin and epigallocatechin-3-gallate synergistically induce apoptosis through inhibition of PI3K/Akt signaling upon depolymerizing microtubules in HeLa cells. $J$ Cell Biochem. 2019;120(4):5987-6003. doi:10.1002/jcb.27886

23. Bhattacharya R, Chatterjee R, Mandal A. et al. Theaflavin-Containing Black Tea Extract: a Potential DNA Methyltransferase Inhibitor in Human Colon Cancer Cells and Ehrlich Ascites Carcinoma-Induced Solid Tumors in Mice. Nutr Cancer;2020. 1-13. doi:10.1080/0163 5581.2020 .1828943

24. Díaz-García VM, Guerrero S, Díaz-Valdivia N, et al. Biomimetic quantum dot-labeled B16F10 murine melanoma cells as a tool to monitor early steps of lung metastasis by in vivo imaging. Int J Nanomed. 2018;13:6391-6412. doi:10.2147/IJN.S165565

25. Becker JC, Houben R, Schrama D, Voigt H, Ugurel S, Reisfeld RA. Mouse models for melanoma: a personal perspective. Exp Dermatol. 2010;19(2):157-164. doi:10.1111/j.1600-0625.2009.00986.x

26. Voltarelli FA, Frajacomo FT, Padilha CS, et al. Syngeneic B16F10 Melanoma Causes Cachexia and Impaired Skeletal Muscle Strength and Locomotor Activity in Mice. Front Physiol. 2017;8:715. doi:10. 3389/fphys.2017.00715

27. Joerger AC, Fersht AR. The p53 Pathway: origins, Inactivation in Cancer, and Emerging Therapeutic Approaches. Annu Rev Biochem. 2016;85(1):375-404. doi:10.1146/annurev-biochem-060815-014710

28. Hussein MR, Haemel AK, Wood GS. Haemel AK and Wood GS. p53-related pathways and the molecular pathogenesis of melanoma. Eur J Cancer Prev. 2003;12(2):93-100. doi:10.1097/00008469-2003 04000-00002

29. Mar VJ, Wong SQ, Li J, et al. BRAF/NRAS wild-type melanomas have a high mutation load correlating with histologic and molecular signatures of UV damage. Clin Cancer Res. 2013;19:4589-4598. doi:10.1158/1078-0432.CCR-13-0398

30. Hainaut P, Hollstein M. p53 and human cancer: the first ten thousand mutations. Adv Cancer Res. 2000;77:81-137.

31. Lu M, Miller P, Lu X. Miller P and $\mathrm{Lu} \mathrm{X}$. Restoring the tumour suppressive function of p53 as a parallel strategy in melanoma therapy. FEBS Lett. 2014;588(16):2616-2621. doi:10.1016/j.febslet. 2014.05.008

32. Chin L. Garraway LA and Fisher DE. Malignant melanoma: genetics and therapeutics in the genomic era. Genes Dev. 2006;20(16): 2149-2182. doi:10.1101/gad.1437206

33. Shen Y, White E. p53-dependent apoptosis pathways. Adv Cancer Res. 2001;82:55-84.

34. Boulares AH, Yakovlev AG, Ivanova V, Stoica BA, Wang G. Iyer $\mathrm{S}$ and Smulson M: role of poly(ADP-ribose) polymerase (PARP) cleavage in apoptosis. Caspase 3-resistant PARP mutant increases rates of apoptosis in transfected cells. J Biol Chem. 1999;274 (33):22932-22940. doi:10.1074/jbc.274.33.22932

35. Cregan SP, MacLaurin JG, Craig CG, Robertson GS, Nicholson DW. Park DS and Slack RS. Bax-dependent caspase-3 activation is a key determinant in $\mathrm{p} 53$-induced apoptosis in neurons. J Neurosci. 1999;19(18):7860-7869. doi:10.1523/JNEUROSCI.1918-07860.1999

36. Satoh MS, Lindahl T. Role of poly(ADP-ribose) formation in DNA repair. Nature. 1992;356(6367):356-358. doi:10.1038/356356a0

37. Kunbo W, Zhonghua L, Jianan H, ALAA El-din B, Fang L, Xinrong D. YUSHUN G AND DONGHE FU. $J$ Food Biochem. 2011;35:1561-1567. 
38. Muller PA, Vousden KH, Norman JC. Vousden KH and Norman JC. p53 and its mutants in tumor cell migration and invasion. J Cell Biol. 2011;192(2):209-218. doi:10.1083/jcb.201009059

39. Lopez-Bergami P. The role of mitogen- and stress-activated protein kinase pathways in melanoma. Pigment Cell Melanoma Res. 2011;24:902-921.

40. Kennedy NJ, Davis RJ. Role of JNK in tumor development. Cell Cycle. 2003;2:199-201.

41. Shieh JM, Huang TF, Hung CF, Chou KH, Tsai Y-J, Wu W-B. Tsai YJ and Wu WB. Activation of c-Jun N-terminal kinase is essential for mitochondrial membrane potential change and apoptosis induced by doxycycline in melanoma cells. $B r J$ Pharmacol. 2010;160 (5):1171-1184. doi:10.1111/j.1476-5381.2010.00746.x

42. Mhaidat NM, Zhang XD, Jiang CC, Hersey P. Jiang CC and Hersey P. Docetaxel-induced apoptosis of human melanoma is mediated by activation of c-Jun NH2-terminal kinase and inhibited by the mitogen-activated protein kinase extracellular signal-regulated kinase 1/2 pathway. Clin Cancer Res. 2007;13(4):1308-1314. doi:10.1158/ 1078-0432.CCR-06-2216

43. Shimada K, Ushijima K, Suzuki C, et al. Yamashita C and Fujimura A. Pulmonary administration of curcumin inhibits B16F10 melanoma lung metastasis and invasion in mice. Cancer Chemother Pharmacol. 2018;82(2):265-273. doi:10.1007/s00280-018-3616-6

44. Ichijo H, Nishida E, Irie $\mathrm{K}$, et al. Induction of apoptosis by ASK1, a mammalian MAPKKK that activates SAPK/JNK and p38 signaling pathways. Science. 1997;275:90-94. doi:10.1126/science.275.5296.90

45. Ivanov VN, Bhoumik A, Ronai Z. Bhoumik A and Ronai Z. Death receptors and melanoma resistance to apoptosis. Oncogene. 2003;22 (20):3152-3161. doi:10.1038/sj.onc.1206456

46. Mandic A, Viktorsson K, Molin M, et al. Linder S and Shoshan MC. Cisplatin induces the proapoptotic conformation of Bak in a deltaMEKK1-dependent manner. Mol Cell Biol. 2001;21:36 84-3691. doi:10.1128/MCB.21.11.3684-3691.2001

47. Kim SH, Yoo ES, Woo JS, Han SH, Lee JH, Jung SH. Kim HJ and Jung JY. Antitumor and apoptotic effects of quercetin on human melanoma cells involving JNK/P38 MAPK signaling activation. Eur J Pharmacol. 2019;860:172568. doi:10.1016/j.ejphar.2019.17 2568

48. Bianchi-Smiraglia A, Paesante S, Bakin AV. Paesante S and Bakin $\mathrm{AV}$. Integrin $\beta 5$ contributes to the tumorigenic potential of breast cancer cells through the Src-FAK and MEK-ERK signaling pathways. Oncogene. 2013;32(25):3049-3058. doi:10.1038/onc.2012.320

49. Castro AF, Campos T, Babcock JT, Armijo ME, Martínez-Conde A. Pincheira R and Quilliam LA. M-Ras induces Ral and JNK activation to regulate $\mathrm{MEK} / \mathrm{ERK}$-independent gene expression in MCF-7 breast cancer cells. J Cell Biochem. 2012;113:1253-1264. doi:10.1002/jcb. 23458

50. Wang AX, Qi XY. Targeting RAS/RAF/MEK/ERK signaling in metastatic melanoma. IUBMB Life. 2013;65:748-758. doi:10.1002/ iub. 1193
51. Shaul YD, The SR. MEK/ERK cascade: from signaling specificity to diverse functions. Biochim Biophys Acta. 1773;1213-1226:2007.

52. Qin J, Xin H, Nickoloff BJ. Specifically targeting ERK1 or ERK2 kills melanoma cells. J Transl Med. 2012;10(1):15. doi:10.1186/ 1479-5876-10-15

53. Davies MA. The role of the PI3K-AKT pathway in melanoma. Cancer J. 2012;18(2):142-147. doi:10.1097/PPO.0b013e31824d448c

54. Meier F, Schittek B, Busch S, et al. The RAS/RAF/MEK/ERK and PI3K/AKT signaling pathways present molecular targets for the effective treatment of advanced melanoma. Front Biosci. 2005;10 (1-3):2986-3001. doi:10.2741/1755

55. Dai DL, Martinka M, Li G. Martinka M and Li G. Prognostic significance of activated Akt expression in melanoma: a clinicopathologic study of 292 cases. J Clin Oncol. 2005;23(7):1473-1482. doi:10.1200/ JCO.2005.07.168

56. Fresno Vara JA, Casado E, De castro J, Cejas P, Belda-Iniesta C, González-Barón M. PI3K/Akt signalling pathway and cancer. Cancer Treat Rev. 2004;30:193-204. doi:10.1016/j.ctrv.2003.07.007

57. Jetzt A, Howe JA, Horn MT, Maxwell E, Yin Z. Johnson D and Kumar CC. Adenoviral-mediated expression of a kinase-dead mutant of Akt induces apoptosis selectively in tumor cells and suppresses tumor growth in mice. Cancer Res. 2003;63:6697-6706.

58. Engelman JA, Chen L, Tan X, et al. Effective use of PI3K and MEK inhibitors to treat mutant Kras G12D and PIK3CA H1047R murine lung cancers. Nat Med. 2008;14(12):1351-1356. doi:10.1038/nm. 1890

59. Jaiswal BS, Janakiraman V, Kljavin NM, et al. Hoeflich KP and Seshagiri S. Combined targeting of BRAF and CRAF or BRAF and PI3K effector pathways is required for efficacy in NRAS mutant tumors. PLoS One. 2009;4:e5717. doi:10.1371/journal.pone.0005717

60. Iqbal J, Abbasi BA, Batool R, et al. Potential phytocompounds for developing breast cancer therapeutics: nature's healing touch. Eur J Pharmacol. 2018;827:125-148.

61. Iqbal J, Abbasi BA, Mahmood T, et al. Plant-derived anticancer agents: a green anticancer approach. Asian Pac J Trop Biomed. 2017;7(12):1129-1150. doi:10.1016/j.apjtb.2017.10.016

62. Iqbal J, Abbasi BA, Ahmad R, et al. Potential phytochemicals in the fight against skin cancer: current landscape and future perspectives. Biomed Pharmacother. 2019;109:1381-1393. doi:10.1016/j.biopha. 2018.10.107

63. Abbasi BA, Iqbal J, Mahmood T, et al. Role of dietary phytochemicals in modulation of miRNA expression: natural swords combating breast cancer. Asian pacific J Tropical Med. 2018.

64. Iqbal J, Abbasi BA, Ahmad R, et al. Ursolic acid a promising candidate in the therapeutics of breast cancer: current status and future implications. Biomed Pharmacother. 2018;108:752-756. doi:10.1016/j.biopha.2018.09.096
OncoTargets and Therapy

\section{Publish your work in this journal}

OncoTargets and Therapy is an international, peer-reviewed, open access journal focusing on the pathological basis of all cancers, potential targets for therapy and treatment protocols employed to improve the management of cancer patients. The journal also focuses on the impact of management programs and new therapeutic agents and protocols on patient perspectives such as quality of life, adherence and satisfaction. The manuscript management system is completely online and includes a very quick and fair peer-review system, which is all easy to use. Visit http://www.dovepress.com/ testimonials.php to read real quotes from published authors. 